\title{
Clinical risk predictors in atrial fibrillation patients following successful coronary stenting: ENTRUST-AF PCI sub-analysis
}

\author{
Andreas Goette ${ }^{1,2,3} \cdot$ Lars Eckardt $^{3,4} \cdot$ Marco Valgimigli $^{5} \cdot$ Thorsten Lewalter $^{3,6,7} \cdot$ Petra Laeis $^{8} \cdot$ Paul-Egbert Reimitz $^{8}$. \\ Rüdiger Smolnik $^{8} \cdot$ Wolfgang Zierhut $^{8}$ • Jan G. Tijssen ${ }^{9,10}$ • Pascal Vranckx ${ }^{11}$
}

Received: 20 August 2020 / Accepted: 7 October 2020 / Published online: 24 October 2020

(c) The Author(s) 2020, corrected publication 2020

\begin{abstract}
Aims This subgroup analysis of the ENTRUST-AF PCI trial (ClinicalTrials.gov Identifier: NCT02866175; Date of registration: August 2016) evaluated type of $\mathrm{AF}$, and $\mathrm{CHA}_{2} \mathrm{DS}_{2}$-VASc score parameters as predictors for clinical outcome.

Methods Patients were randomly assigned after percutaneous coronary intervention (PCI) to either edoxaban $(60 \mathrm{mg} / 30 \mathrm{mg}$ once daily [OD]; $n=751)$ plus a $\mathrm{P}_{2} \mathrm{Y}_{12}$ inhibitor for 12 months or a vitamin $\mathrm{K}$ antagonist [VKA] $(n=755)$ plus a P2 $\mathrm{Y}_{12}$ inhibitor and aspirin (100 mg OD, for 1-12 months). The primary outcome was a composite of major/clinically relevant non-major bleeding (CRNM) within 12 months. The composite efficacy endpoint consisted of cardiovascular death, stroke, systemic embolic events, myocardial infarction (MI), and definite stent thrombosis.

Results Major/CRNM bleeding event rates were 20.7\%/year and 25.6\%/year with edoxaban and warfarin, respectively (HR [95\% CI]: 0.83 [0.654-1.047]). The event rates of composite outcome were $7.26 \% / y e a r$ and $6.86 \% / y e a r$, respectively (HR [95\% CI]): $1.06[0.711-1.587]$ ), and of overall net clinical benefit were $12.48 \%$ year and $12.80 \%$ year, respectively (HR [(95\% CI]: 0.99 [(0.730; 1.343]). Increasing $\mathrm{CHA}_{2} \mathrm{DS}_{2}$-VASc score was associated with increased rates of all outcomes. $\mathrm{CHA}_{2} \mathrm{DS}_{2}$-VASc score $\geq 5$ was a marker for stent thrombosis. Paroxysmal AF was associated with a higher occurrence of MI (4.87\% versus $2.01 \%, p=0.0024)$.

Conclusion After PCI in AF patients, increasing $\mathrm{CHA}_{2} \mathrm{DS}_{2}$-VASc score was associated with increased bleeding rates and $\mathrm{CHA}_{2} \mathrm{DS}_{2}$-VASc score $(\geq 5)$ predicted the occurrence of stent thrombosis. Paroxysmal AF was associated with MI. These findings may have important clinical implications in AF patients.
\end{abstract}

Keywords Atrial fibrillation $\cdot$ Coronary stenting $\cdot \mathrm{NOACs} \cdot \mathrm{CHA}_{2} \mathrm{DS}_{2}$-VASc $\cdot$ Edoxaban

\section{Introduction}

Around $15 \%$ of patients with atrial fibrillation (AF) have associated coronary artery disease which may require percutaneous coronary intervention (PCI) [1]. In these patients, oral anticoagulation is necessary for stroke prevention and antiplatelet therapy to prevent stent thrombosis, myocardial infarction (MI), and the need for urgent repeat revascularization all of which need to be balanced against the increased

Andreas Goette

andreas.goette@vincenz.de

Extended author information available on the last page of the article risk of bleeding [2]. Overall, it remains unclear how clinical outcome after PCI can be predicted in AF patients.

The optimal combination of novel anticoagulant agents, as well as the duration of treatment, for patients with acute coronary syndrome (ACS) or elective PCI along with coexisting $\mathrm{AF}$ have been studied in four randomised clinical trials [2-5]. Although the 2017 ESC focussed update on dual antiplatelet therapy recommended a triple-therapy strategy as short as possible (consisting of an oral anticoagulant, aspirin $75-100 \mathrm{mg}$, and clopidogrel $75 \mathrm{mg}$ once daily) in AF patients presenting with ACS and/or undergoing PCI [6], studies have shown an increase in the absolute risk of major haemorrhage associated with co-prescription of an oral anticoagulant with antiplatelet therapy, in particular triple therapy $[2-5,7,8]$.

Findings from non-vitamin $\mathrm{K}$ antagonist oral anticoagulant (NOAC) trials [2-5] have reported reduced bleeding 
events in patients receiving dual antithrombotic therapy (DAT) combining an NOAC and a P2 $\mathrm{Y}_{12}$ inhibitor versus triple antithrombotic therapy (TAT) consisting of a vitamin $\mathrm{K}$ antagonist (VKA), a $\mathrm{P} 2 \mathrm{Y}_{12}$ inhibitor, and aspirin.

The ENTRUST-AF PCI study (NCT02866175) was a randomised, multicentre, open-label, non-inferiority phase $3 \mathrm{~b}$ trial with masked outcome evaluation at 186 sites in 18 countries [2]. In this trial, the edoxaban-based regimen was non-inferior for bleeding compared with the VKA-based regimen, without significant differences in ischaemic events [2].

Although the $\mathrm{CHA}_{2} \mathrm{DS}_{2}$-VASc score is used and validated in $\mathrm{AF}$ patients $[9,10]$, there is limited evidence for validity of the $\mathrm{CHA}_{2} \mathrm{DS}_{2}$-VASc score in patients with AF following PCI [11]. Therefore, it remains unclear if the score is useful to predict bleeding and ischaemic outcomes in this subset of patients. Of note, the highest prevalence of left atrial thrombi has been reported in AF patients aged $\geq 75$ years combined with a history of congestive heart failure (CHF), whereas ventricular ischaemia appears to be related to paroxysmal AF [10,12]. Thus, these specific sub-cohorts of AF patients may also have high adverse event rates after PCI.

The present subgroup analysis of the ENTRUST-AF PCI trial evaluated $\mathrm{CHA}_{2} \mathrm{DS}_{2}$-VASc score, age, history of CHF, and type of $\mathrm{AF}$ as potential determinants for the risk of bleeding, MACE (including MI) and any stent thrombosis, as well as for net clinical benefit.

\section{Methods}

In the ENTRUST-AF PCI trial, patients with AF were investigated after successful coronary stenting. The study design and primary trial results were previously described in more detail [2, 13]. In brief, patients were randomly assigned (1:1) from $4 \mathrm{~h}$ to 5 days after PCI to either edoxaban $(60 \mathrm{mg}$ once daily, or dose reduced to $30 \mathrm{mg}$ per day; $n=751$ ) plus a P2 $Y_{12}$ inhibitor for 12 months or a VKA $(n=755)$ in combination with a P2 $\mathrm{Y}_{12}$ inhibitor and aspirin (100 mg once daily, for 1-12 months). The dose of edoxaban could be reduced by $50 \%$ in patients with the following clinical characteristics: creatinine clearance $15-50 \mathrm{~mL} / \mathrm{min}$, bodyweight $\leq 60 \mathrm{~kg}$, or concomitant use of specified potent P-glycoprotein inhibitors (cyclosporine, dronedarone, erythromycin, or ketoconazole).

The primary outcome was a composite of major or clinically relevant non-major (CRNM) bleeding within 12 months. The primary efficacy outcome was the composite of cardiovascular death, stroke, systemic embolic events (SEE), MI, and definite stent thrombosis. Other secondary outcomes include net clinical benefit, defined as the composite of cardiovascular disease, stroke, SEE, spontaneous MI, definite stent thrombosis, and International Society on Thrombosis and Haemostasis (ISTH) defined major bleeding. Any stent thrombosis is defined as a composite of definite, probable, and possible stent thrombosis (as per ARC consensus definitions). Definite stent thrombosis was a secondary endpoint, while statistical analysis of any stent thrombosis was performed post hoc. All suspected endpoint events were adjudicated by an independent Clinical Events Committee in a blinded manner and without any knowledge of the subject's assigned treatment regimen $[2,13]$.

Patients were categorised by age groups $(<75$ years $I \geq 75$ years), presence or absence of history of CHF, and type of AF (paroxysmal, persistent, long-standing persistent and permanent; definition according to 2016 ESC/EACTS Guidelines for the management of atrial fibrillation [7]) to assess the effects on primary and secondary outcomes in the overall population and separately in patients receiving edoxaban and warfarin. All statistical analyses should be interpreted in a purely descriptive exploratory way.

Similar to post hoc landmark analyses on primary parameters, a post hoc landmark analysis was performed with a landmark at Day 14 regarding the net clinical benefit. The landmark at 14 days was selected based on the international normalised ratio distribution over time and inspection of the Kaplan-Meier curve.

The study was conducted in accordance with the Declaration of Helsinki, International Conference on Harmonisation guidelines on Good Clinical Practice (ICH E6), and applicable regulatory requirements. The final study protocol and informed consent form were reviewed and approved by the ethics boards/institutional review boards and corresponding health authorities for all participating study sites.

\section{Results}

Overall, 1,506 patients were randomised after a median time from PCI to randomisation of $45.1 \mathrm{~h}$ (interquartile range [IQR] 22.2-76.2). Major or CRNM bleeding event rates were $20.7 \%$ year and $25.6 \% /$ year in patients receiving edoxaban and warfarin, respectively (hazard ratio [HR] [95\% confidence interval (CI)]): 0.83 [(0.654-1.047]). The event rates of primary composite outcome of cardiovascular death, stroke, SEE, MI, and definite stent thrombosis were $7.26 \% /$ year and 6.86\%year in patients receiving edoxaban and warfarin, respectively (HR [95\% CI]): 1.06 [0.711-1.587]).

\section{$\mathrm{CHA}_{2} \mathrm{DS}_{2}$-VASc score}

In patients categorised by $\mathrm{CHAD}_{2} \mathrm{DS}_{2}$-VASC score $(0-2,3$, 4, 5, 6-9), increasing $\mathrm{CHA}_{2} \mathrm{DS}_{2}$-VASc score was associated with increased major or CRNM bleeding (Fig. 1). Similar to the $\mathrm{CHA}_{2} \mathrm{DS}_{2}$-VASc score, HAS-BLED score predicted bleeding (Table 1). Increasing $\mathrm{CHA}_{2} \mathrm{DS}_{2}$-VASc score was also associated with increased events of primary efficacy and 


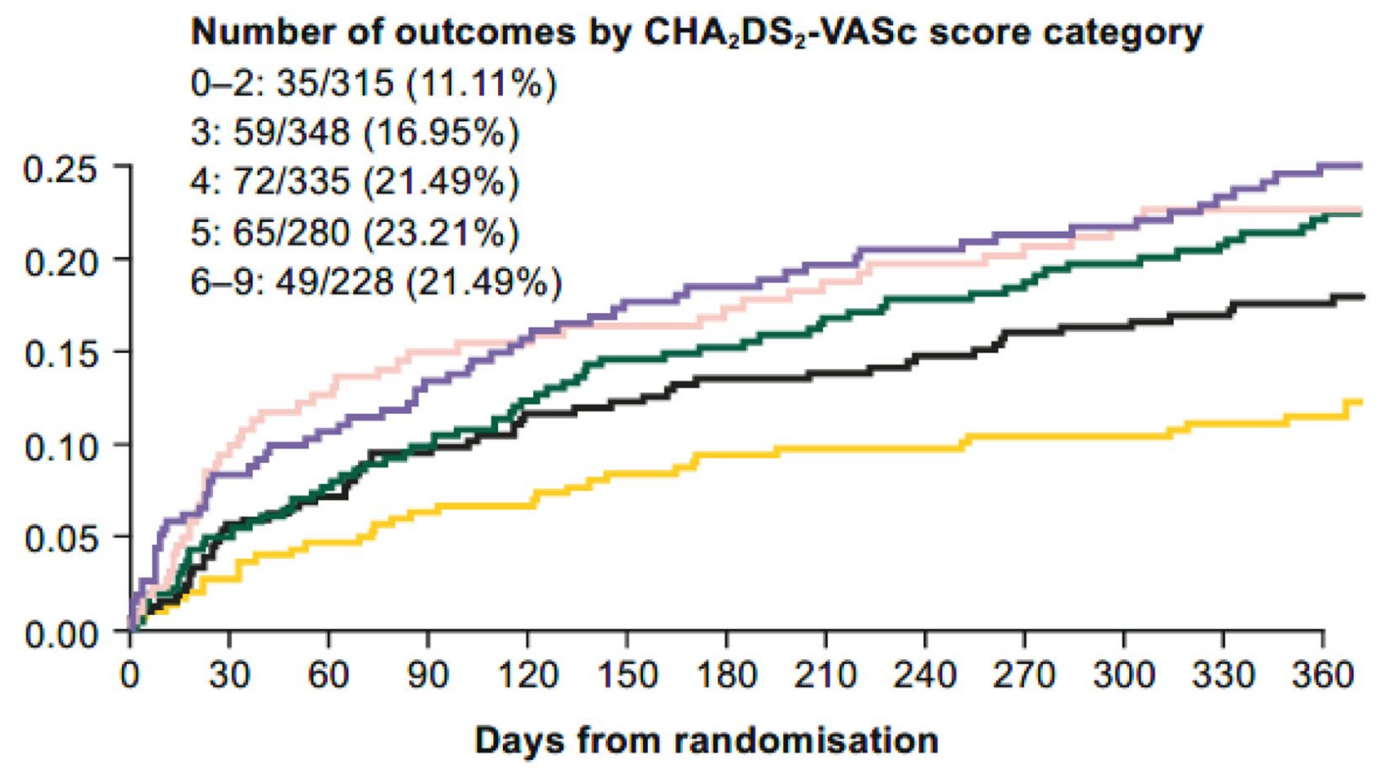

Number at risk:

$\begin{array}{ll}- & 0-2 \\ - & 3 \\ - & 4 \\ - & 5 \\ - & 6-9\end{array}$

$\begin{array}{lll}315 & 295 & 284\end{array}$

$\begin{array}{lll}348 & 317 & 310\end{array}$

278

299288

$275 \quad 270$

265

285

$\begin{array}{llll}335 & 311 & 298 & 287\end{array}$

$\begin{array}{llll}280 & 245 & 232 & 224\end{array}$

277

268

183179

280

265

203

$198 \quad 189$

179177

174169

263263

279276

$257 \quad 252$

$\begin{array}{llll}260 & 259 & 257 & 238\end{array}$

$\begin{array}{llll}271 & 270 & 268 & 239\end{array}$

$\begin{array}{llll}249 & 243 & 239 & 219\end{array}$

$\begin{array}{lllll}196 & 194 & 190 & 185 & 158\end{array}$

Fig. 1 Time to first major or CRNM bleeding by $\mathrm{CHA}_{2} \mathrm{DS}_{2}$-VASc category. $C R N M$ clinically relevant non-major

Table 1 Frequency of primary composite outcome (major or CRNM bleeding [ISTH]) by HAS-BLED score category

\begin{tabular}{lll}
\hline HAS-BLED score category & \multicolumn{2}{l}{ Primary composite outcome } \\
\cline { 2 - 3 } & Events/N & $\%$ \\
\hline missing & $12 / 93$ & 12.90 \\
$1-2$ & $62 / 443$ & 14.00 \\
3 & $141 / 708$ & 19.92 \\
$4-7$ & $65 / 262$ & 24.81 \\
\hline
\end{tabular}

The HAS-BLED score has only been calculated if all nine items were non-missing

Table 2 Frequency of primary composite outcome and net clinical benefit by $\mathrm{CHA}_{2} \mathrm{DS}_{2}$-VASc score category

\begin{tabular}{|c|c|c|c|c|}
\hline \multirow[t]{2}{*}{$\begin{array}{l}\mathrm{CHA}_{2} \mathrm{DS}_{2} \text {-VASc } \\
\text { score category }\end{array}$} & \multicolumn{2}{|c|}{$\begin{array}{l}\text { Primary composite } \\
\text { outcome }\end{array}$} & \multicolumn{2}{|c|}{ Net clinical benefit } \\
\hline & Events/N & $\%$ & Events/N & $\%$ \\
\hline $0-2$ & $12 / 315$ & 3.81 & $17 / 315$ & 5.40 \\
\hline 3 & $19 / 348$ & 5.46 & $30 / 348$ & 8.62 \\
\hline 4 & $23 / 335$ & 6.87 & $50 / 335$ & 14.93 \\
\hline 5 & $20 / 280$ & 7.14 & $35 / 280$ & 12.50 \\
\hline $6-9$ & $21 / 228$ & 9.21 & $33 / 228$ & 14.47 \\
\hline
\end{tabular}

net clinical benefit (Table 2). The effect of edoxaban versus VKA was consistent independent of the $\mathrm{CHA}_{2} \mathrm{DS}_{2}$-VASc score. The event rates of definite (14 cases) and probable (9 cases) stent thromboses were very low [2]. Of note, $\mathrm{CHA}_{2} \mathrm{DS}_{2}$-VASc score $\geq 5$ was a marker for occurrence of any stent thrombosis during follow-up (Fig. 2).

\section{Age, history of CHF, and AF type}

A recent imaging study has clearly shown that age above 75 years and a history of $\mathrm{CHF}$ are the main factors leading to atrial clot formation in AF [10]. Therefore, we analysed these factors in more detail in the PCI setting. Major or CRNM bleeding was not significantly different in patients aged $\geq 75$ years compared with those aged $<75$ years (Fig. 3a). For patients categorised by age classes $(<75$ $/ \geq 75$ years), history of CHF (yes/no), and the combinations of both parameters, the $p_{\text {interaction }}$ for major or CRNM bleeding, were $0.98,0.11$, and 0.39 , respectively. In patients aged $<75$ years and no history of CHF, there was a lower risk of major or CRNM bleeding in those receiving edoxaban versus warfarin. 
Fig. 2 Frequency of any stent thrombosis by $\mathrm{CHA}_{2} \mathrm{DS}_{2}$-VASc score category

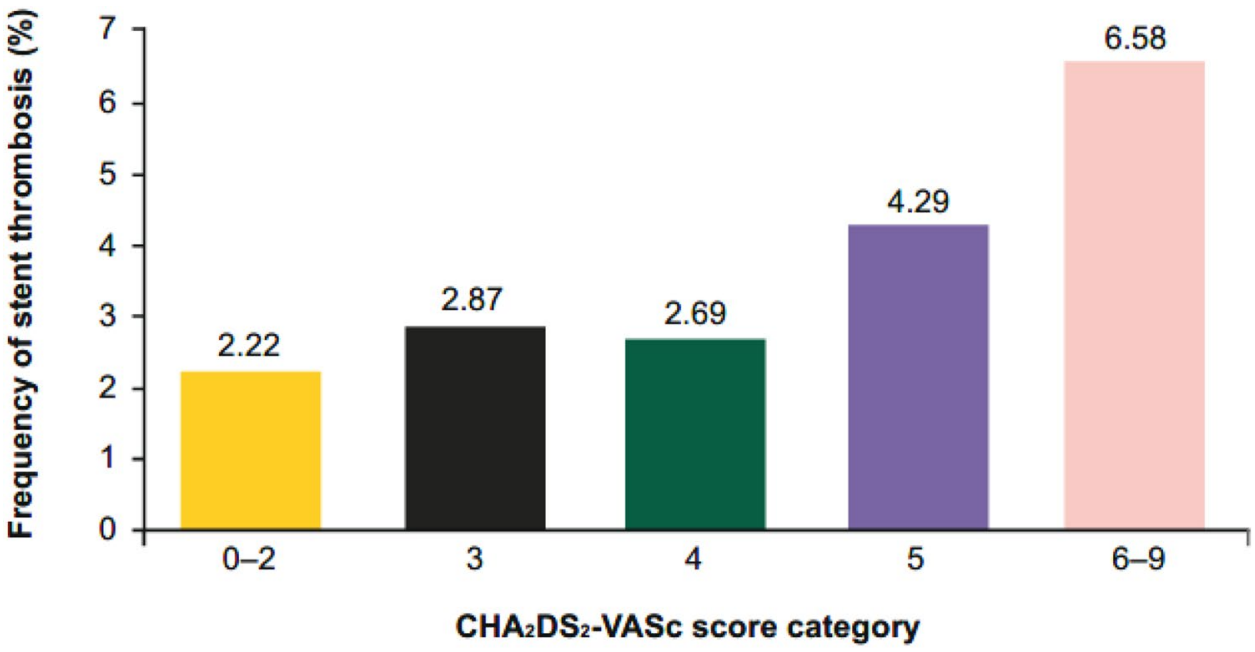

\section{Discussion}

combinations of both for the primary composite outcome (Fig. $3 \mathrm{~b}$ ); $p_{\text {interaction }}$ were $0.34,0.57$, and 0.70 , respectively.

There was no interaction of AF type for major or CRNM bleeding and composite efficacy (Figs. $3 \mathrm{a}$ and $3 \mathrm{~b}$ ). In contrast to non-paroxysmal $\mathrm{AF}$, paroxysmal $\mathrm{AF}$ at baseline was associated with a higher occurrence of MI $(4.87 \%$ versus $2.01 \%, p=0.0024$ ) (Fig. 4, Table 3). Differences in the occurrence of MI cannot be explained by number of stent thromboses (stent thrombosis in patients with paroxysmal AF 30/760, 3.9\% versus non-paroxysmal AF 23/745, 3.1\%, $p=$ non-significant).

\section{Net clinical benefit}

The event rates of overall net clinical benefit (composite of death from cardiovascular causes, stroke, systemic embolic events, MI, definite stent thrombosis, and major bleeding) were $12.48 \%$ /year and $12.80 \%$ /year in the edoxaban and warfarin dose groups, respectively (HR [ $(95 \% \mathrm{CI}]: 0.99$ [(0.730; 1.343]) (Fig. 3c).

There was no interaction of age, history of CHF, or combinations of both for the net clinical benefit outcome (Fig. 3c); $p_{\text {interaction }}$ were $0.73,0.49$, and 0.87 , respectively. Furthermore, there was no interaction of AF type for the net clinical benefit (Fig. 3c).

A post hoc analysis with a landmark at 14 days, and from 15 days to 1 year provided a clear signal of heterogeneity with respect to the net clinical benefit $\left(p_{\text {interaction }}<0.0001\right.$; Fig. 5).

A lower risk of net clinical composite outcome was noted for the warfarin dose group versus the edoxaban group (HR [95\% CI]: 3.69 [1.50-9.11]) in the first 14 days, followed by a lower risk of net clinical composite outcome favouring the edoxaban regimen (HR [95\% CI]: 0.78 [0.56-1.09]).
The ENTRUST-AF PCI subgroup analysis showed that the effect of edoxaban versus VKA on study outcomes was consistent independent of $\mathrm{CHAD}_{2} \mathrm{DS}_{2}$-VASc parameters. This is in line with the findings reported in the primary analysis that showed non-inferiority of edoxaban-based regimen compared with the VKA-based regimen for bleeding events, without significant differences in ischaemic events [2].

The coexistence of AF and the need for PCI lead to a higher risk of developing thrombotic and bleeding complications. However, risk stratification in patients requiring dual antithrombotic treatment strategies has not been fully investigated so far. The $\mathrm{CHA}_{2} \mathrm{DS}_{2}$-VASc score was introduced for risk stratification of systemic and cerebral ischaemic events in AF patients. Furthermore, it was shown that this score is useful to predict the overall bleeding risk in AF cohorts [14]. A retrospective study conducted comparative validation of the 6-month GRACE (Global Registry of Acute Coronary Events) risk score and $\mathrm{CHA}_{2} \mathrm{DS}_{2}$-VASc risk score to predict the risk of post-ACS ischaemic stroke [15]. The GRACE risk score was based on nine prognostic variables including age, history of HF, history of acute MI, heart rate, systolic blood pressure, ST-segment depression, serum creatinine levels at admission, elevated myocardial necrosis markers or enzymes, and lack of PCI revascularisation during admission. Both $\mathrm{CHA}_{2} \mathrm{DS}_{2}$-VASc and GRACE risk scores were powerful predictors of stroke incidence during follow-up.

The present analysis suggests that the $\mathrm{CHA}_{2} \mathrm{DS}_{2}$-VASc score is useful to predict bleeding and ischaemic events in AF patients after a successful PCI. Thus, regardless of the treatment regimen of triple or dual therapy, the $\mathrm{CHA}_{2} \mathrm{DS}_{2}$-VASc score is a predictor of adverse clinical outcomes.

In post-PCI patients, stent thrombosis is an event with a substantial risk of death. So far, there is no clinically useful 
Fig. 3 Major or CRNM bleeding (a), primary efficacy (b), and net clinical benefit outcomes (c) for patients treated with edoxaban- or VKA-based regimen

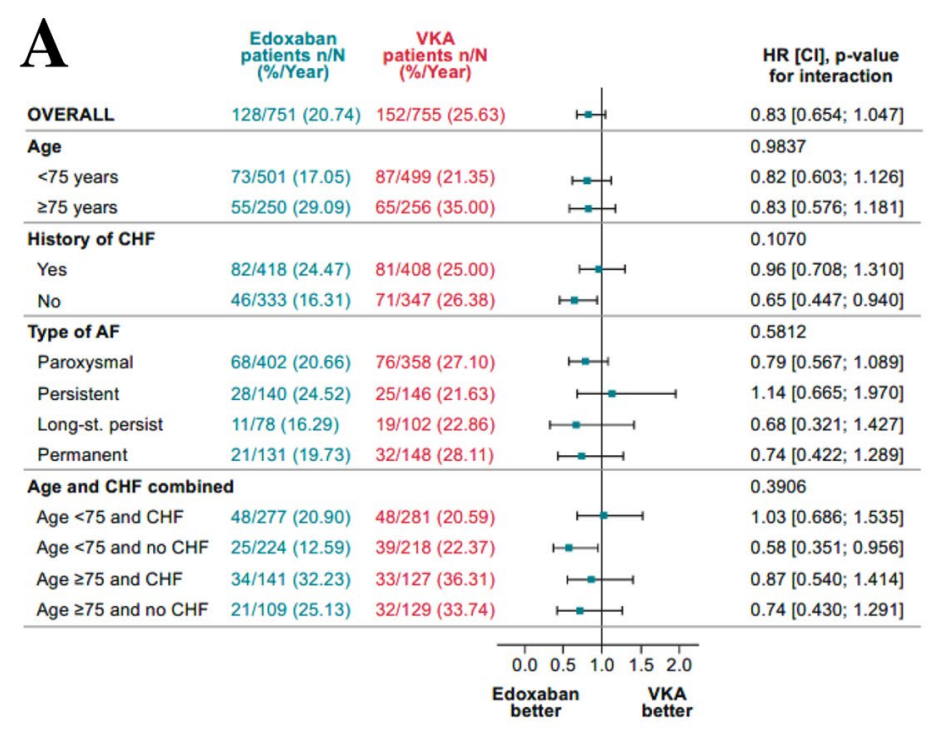

B

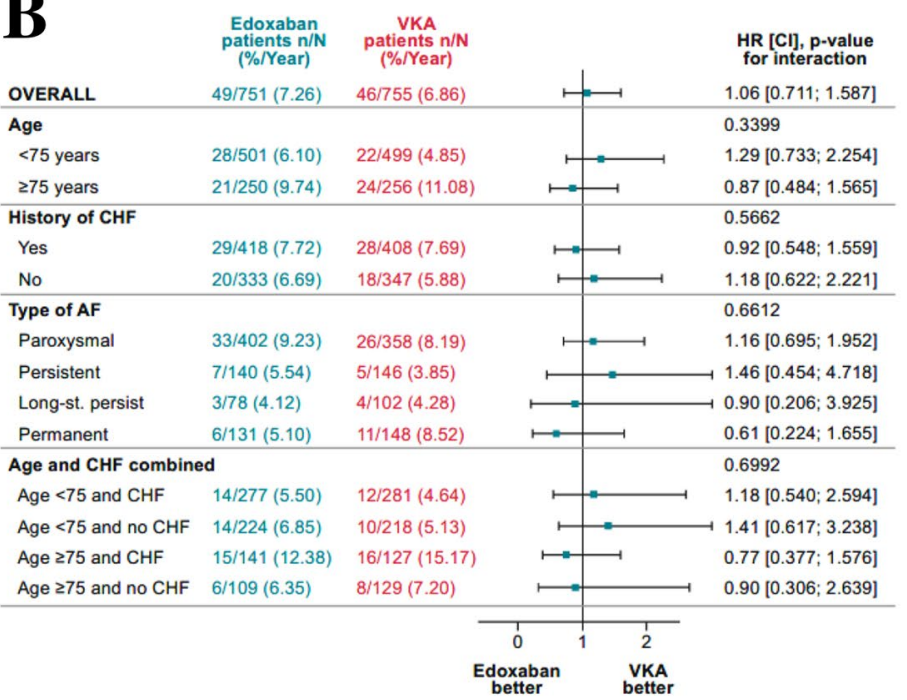

C

\begin{tabular}{|c|c|c|c|c|c|}
\hline $\mathcal{U}$ & $\begin{array}{c}\begin{array}{c}\text { Edoxaban } \\
\text { patients n/N }\end{array} \\
\text { (\%/Year) }\end{array}$ & $\begin{array}{c}\text { VKA } \\
\text { patients n/N } \\
(\% / Y e a r)\end{array}$ & \multirow{2}{*}{\multicolumn{2}{|c|}{$\mapsto$}} & $\begin{array}{l}\mathrm{HR}[\mathrm{Cl}], \mathrm{p} \text {-value } \\
\text { for interaction }\end{array}$ \\
\hline OVERALL & $82 / 751(12.48)$ & $83 / 755(12.80)$ & & & $0.99[0.730 ; 1.343]$ \\
\hline \multicolumn{2}{|l|}{ Age } & & & & 0.7310 \\
\hline$<75$ years & $44 / 501$ (9.72) & $42 / 499(9.54)$ & $\mapsto$ & $\longrightarrow$ & $1.04[0.680 ; 1.587]$ \\
\hline$\geq 75$ years & $38 / 250(18.63)$ & $41 / 256(19.67)$ & $\mapsto$ & $\longrightarrow$ & $0.93[0.601 ; 1.455]$ \\
\hline \multicolumn{2}{|l|}{ History of $\mathrm{CHF}$} & & & & 0.4891 \\
\hline Yes & $50 / 418(13.71)$ & $44 / 408(12.35)$ & $\vdash$ & $\longmapsto$ & $1.06[0.712 ; 1.592]$ \\
\hline No & $32 / 333(10.96)$ & $39 / 347$ (13.35) & $\longmapsto$ & 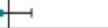 & $0.85[0.528 ; 1.358]$ \\
\hline \multicolumn{2}{|l|}{ Type of AF } & & & & 0.5517 \\
\hline Paroxysmal & $49 / 402(14.14)$ & $43 / 358(14.06)$ & $\vdash$ & $\longrightarrow$ & $1.02[0.677 ; 1.545]$ \\
\hline Persistent & $13 / 140(10.56)$ & $9 / 146(7.07)$ & & & $1.60[0.657 ; 3.913]$ \\
\hline Long-st. persist & $6 / 78(8.29)$ & $12 / 102(13.56)$ & $\longmapsto$ & -1 & $0.55[0.201 ; 1.492]$ \\
\hline Permanent & 14/131 (12.19) & 19/148 (14.98) & $\longmapsto$ & $\longrightarrow$ & $0.84[0.417 ; 1.702]$ \\
\hline \multicolumn{3}{|l|}{ Age and CHF combined } & & & 0.8663 \\
\hline Age $<75$ and $\mathrm{CHF}$ & 25/277 (9.99) & $21 / 281(8.34)$ & & & $1.18[0.658 ; 2.117]$ \\
\hline Age $<75$ and no $\mathrm{CHF}$ & $19 / 224(9.38)$ & $21 / 218(11.16)$ & $\longmapsto$ & $\rightarrow$ & $0.86[0.456 ; 1.614]$ \\
\hline Age 275 and $\mathrm{CHF}$ & 25/141 (21.84) & $23 / 127(22.03)$ & • & & $0.97[0.547 ; 1.715]$ \\
\hline \multirow[t]{3}{*}{ Age $\geq 75$ and no $\mathrm{CHF}$} & $13 / 109(14.52)$ & $18 / 129(17.31)$ & $\longmapsto$ & $\longrightarrow$ & $0.83[0.407 ; 1.700]$ \\
\hline & & & & 2 & \\
\hline & & & $\begin{array}{l}\text { kaban } \\
\text { tter }\end{array}$ & $\begin{array}{l}\text { VKA } \\
\text { better }\end{array}$ & \\
\hline
\end{tabular}


Fig. 4 Frequency of myocardial infarction by atrial fibrillation subtype. AF, atrial fibrillation; MI, myocardial infarction

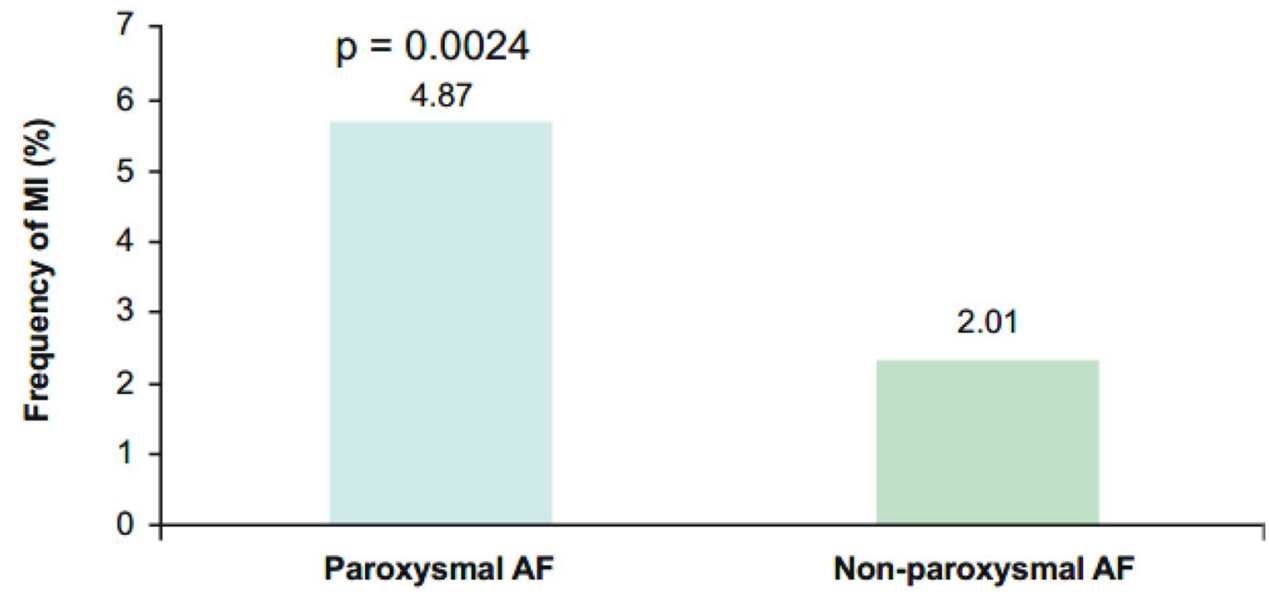

Table 3 Type of myocardial infarction by the category of atrial fibrillation

\begin{tabular}{llll}
\hline Type of MI & $\begin{array}{l}\text { Paroxysmal } \\
(N=760)\end{array}$ & $\begin{array}{l}\text { Non-paroxysmal } \\
(N=745)\end{array}$ & $\begin{array}{l}\text { Total } \\
(N=1505)^{\mathrm{a}}\end{array}$ \\
\hline MI type 1: Spontaneous MI & 15 & 8 & 23 \\
MI type 2: MI secondary to an ischaemic event & 6 & 2 & 8 \\
MI type 3: MI resulting in death when biomarker & 1 & 0 & 1 \\
$\quad$ values are unavailable & 8 & 4 & 12 \\
MI type 4b: MI related to stent thrombosis & 7 & 1 & 8 \\
MI type 4c: MI related to restenosis & 37 & 15 & 52 \\
Total & & & \\
\hline
\end{tabular}

MI types 4a and 5 did not occur; both types were adjudicated per definition of the Society for Cardiovascular Angiography and Interventions (SCAI)

a 1 missing. MI, myocardial infarction scoring system to predict stent thrombosis in AF patients. The present analysis points for the first time towards the $\mathrm{CHA}_{2} \mathrm{DS}_{2}$-VASc score being a predictor of stent thrombosis in post-PCI AF patients. In patients with $\mathrm{CHA}_{2} \mathrm{DS}_{2}$-VASc scores up to 4 , the incidence of any stent thrombosis is in a comparable range as in the AUGUSTUS trial [16]. However, in patients with $\mathrm{CHA}_{2} \mathrm{DS}_{2}$-VASc scores above 4 , we observed a marked increase in the risk of stent thrombosis. This new finding may have some key clinical implications. While in the edoxaban group, the vast majority of definite or probable stent thromboses (11/13) occurred within the first 30 days after randomisation, in the VKA group, the majority of definite or probable stent thromboses $(8 / 10)$ occurred after day 30 following randomisation [17]. Of note, the prediction of total number of stent thromboses with the $\mathrm{CHA}_{2} \mathrm{DS}_{2}$-VASc score was independent of the therapeutic approach with triple versus dual therapy. Overall, our analysis showed that increasing $\mathrm{CHA}_{2} \mathrm{DS}_{2}$-VASc scores were associated with increased events of major or CRNM bleeding, primary outcome, and net clinical benefit in AF patients who underwent PCI.

A landmark analysis for the primary study endpoint has been previously published showing a significant reduction in the rate of the primary bleeding outcome favouring the edoxaban regimen after day 14 [2]. A consistent approach has also been used for the comparison of ACS with chronic coronary syndrome [17]. For the analysis of net clinical benefit with a landmark at day 14 , the pattern is similar to the primary study endpoint including a significant heterogeneity with respect to the treatment effect $\left(p_{\text {interaction }}<0.0001\right)$. However, after the landmark, the net clinical benefit for edoxaban does not reach significance.

The relationship between AF pattern and the risk of adverse outcomes has not been fully explored. A registry demonstrated higher event rates of stroke in persistent versus paroxysmal AF [18]. Furthermore, as noted earlier, the sub-analysis of the ENSURE-AF cardioversion trial pointed towards an increased rate of MI in patients with paroxysmal versus persistent AF [12]. This finding is supported by the present data set, which suggests an increased rate of MI postPCI in paroxysmal versus non-paroxysmal AF patients.

Pathophysiologically, there are major differences between paroxysmal and persistent AF [19, 20]. Brief episodes of AF induce microcirculatory flow alterations in the ventricles [19]. Thereby, AF induces angina pectoris, low grade of ischaemia characterised by troponin $\mathrm{T}$ elevation and a type 


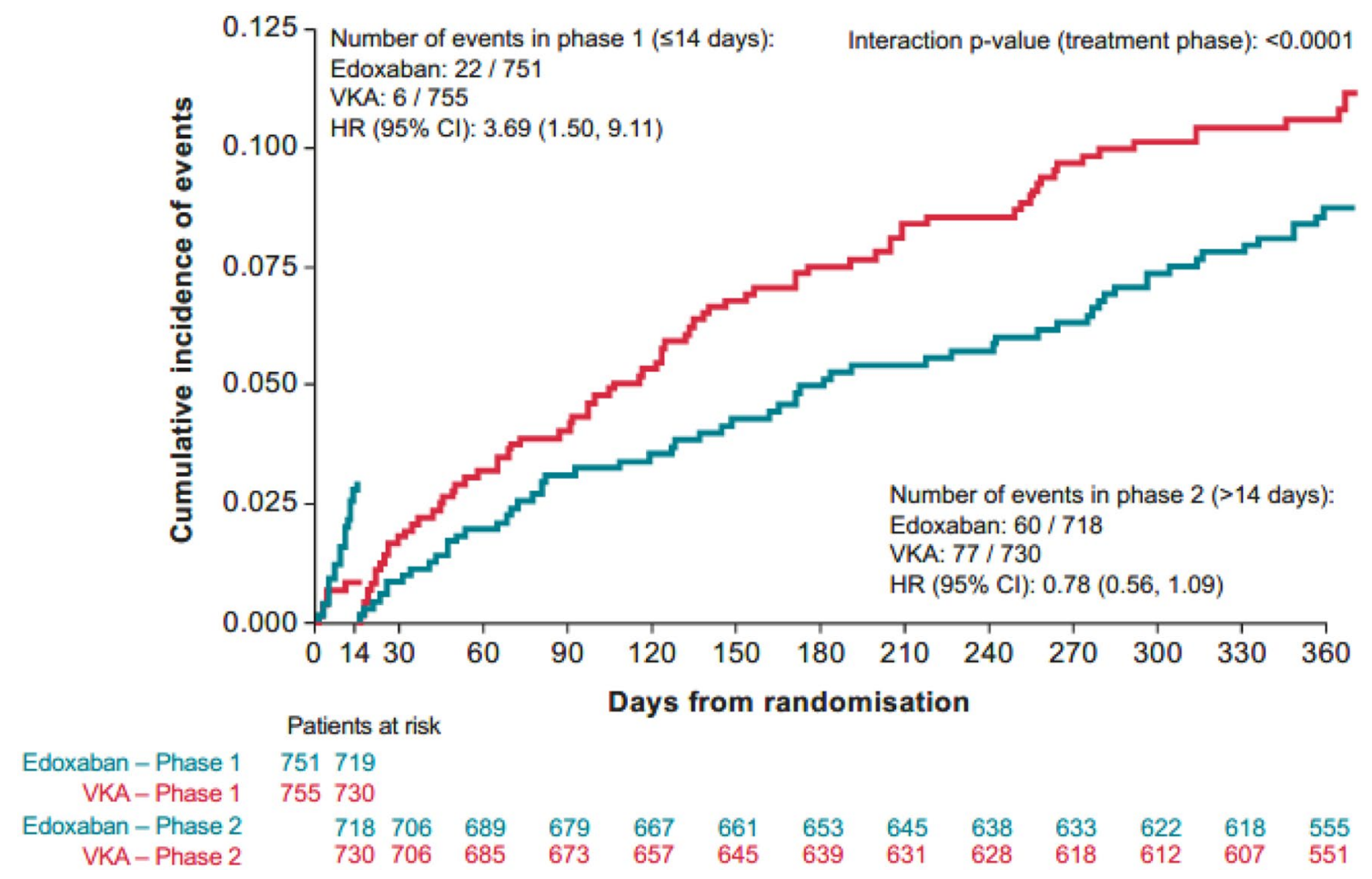

Fig. 5 Landmark analysis of net clinical benefit with a landmark set at day 14. Landmark analysis 14 days, 14 days NCB, ITT, overall period +3 days. ITT intention to treat, $H R$ hazard ratio, $N C B$ net clinical benefit, $V K A$ vitamin $\mathrm{K}$ antagonist

2 MI $[19,21]$. If a chronic coronary syndrome is already present, such as in all the patients in the ENTRUST-AF PCI trial, an increased and irregular ventricular rate after initiation of AF contributes to impaired blood flow across coronary artery stenosis [21]. At the cellular level, lack of nitric oxide due to the action of reactive oxygen species and oxidative stress appears to be the driver for the flow abnormalities in the ventricular myocardium [19]. Thus, paroxysmal AF has been shown to be associated with ventricular ischaemia in animal models $[19,21]$. In contrast to paroxysmal AF, oxidative stress is counterbalanced by downregulation of oxidative stress enzymes and signaling pathways in persistent AF [19]. Thereby, the occurrence of angina pectoris and ventricular ischaemia directly induced by AF is less likely to occur [22]. However, constantly increased ventricular rates during persistent AF patients have been shown to induce a tachycardia-induced cardiomyopathy and heart failure [19, 22].

\section{Limitations}

All retrospective subgroup analyses of clinical trials are subject to many limitations. Such observations should be viewed as hypothesis-generating only. One limitation of this analysis is that the burden of AF or AF recurrences were not systematically assessed during the follow-up period. No constant rhythm monitoring was done. However, 1 year of follow-up may not be long enough to change the pre-existing type of AF. The study was too small to elaborate differences in various treatments regimens (triple versus dual therapy) in accordance to the risk score system. Net clinical benefit was a pre-specified secondary outcome of the study. However, due to the fact that the study did not show a statistically significant difference in the primary endpoint, net clinical benefit is hypothesis-generating and should be interpreted with caution. Moreover, a statistically powered analysis appears difficult due to the overall small events rates. This includes the results regarding stent thromboses which are based on a total of 23 events only for definite plus probable stent thromboses (53 events for any stent thromboses).

\section{Conclusions}

The effect of edoxaban versus VKA in the present cohort was consistent independent of AF-specific stroke risk factors. Of note, increasing $\mathrm{CHA}_{2} \mathrm{DS}_{2}$-VASc score was associated with increased bleeding events and a $\mathrm{CHA}_{2} \mathrm{DS}_{2}-\mathrm{VASc}$ score $\geq 5$ predicted the occurrence of stent thrombosis. Paroxysmal AF at baseline appeared to be a risk factor for MI during follow-up. These findings may have important clinical implications. 
Acknowledgements Editorial support was provided by Shelley Narula from inScience Communications, Springer Healthcare Ltd, UK, and was funded by Daiichi Sankyo Europe GmbH, Munich, Germany in accordance with Good Publication Practice guidelines (https://www. ismpp.org/gpp3).

Author contributions AG and PV were co-principal investigators. PV, AG, LE, MV, TL, and JT were collaborators and were involved in the design of the study and its implementation and contributed to all revisions of the manuscript. PL was the study coordinator. RS and WZ contributed to revision of the manuscript. PER did the statistical analysis and contributed to all revisions of the manuscript. All authors read and approved the final manuscript.

Funding Open Access funding enabled and organized by Projekt DEAL. This study was supported by Daiichi Sankyo Europe GmbH, Munich, Germany.

Data availability statement The ENTRUST-AF PCI trial is sponsored by Daiichi Sankyo. Multiple substudies are predefined. Internal investigators, who actively participated in the study, and who provide a methodologically sound study proposal will be granted priority access to the study data for 60 months. After 60 months, access is extended to external investigators not affiliated to the trial. Study proposals can be filed at the Vivli website. For data access requests, see https://vivli.org/.

\section{Compliance with ethical standards}

Conflict of interest Andreas Goette discloses honoraria and speaker fees from Astra Zeneca, Bayer Health Care, Berlin-Chemie, BristolMyers Squibb/Pfizer, Boehringer Ingelheim, Boston Scientific, Daiichi Sankyo, Medtronic, Novartis, and Omeicos. Research has been supported by Josef-Freitag Stiftung and Deutsche Herzstiftung e.V. outside the submitted work. Thorsten Lewalter reports personal fees from Abbott, Boston Scientific, Bayer, Boehringer, Daiichi Sankyo, and Pfizer outside the submitted work. Marco Valgimigli reports grants and personal fees from Abbott, Alvimedica, Amgen, Bayer, BristolMyers Squibb SA, Coreflow, Daiichi Sankyo, Vifor, Idorsia, Terumo, and iVascular; grants and personal fees from grants from AstraZeneca and Medicure, outside the submitted work. Lars Eckardt discloses consultant fees, speaking honoraria, and travel expenses from Abbott, Bayer Healthcare, Biosense Webster, Biotronik, Boehringer, Boston Scientific, Bristol-Myers Squibb, Daiichi Sankyo, Medtronic, Pfizer, and Sanofi Aventis. Research has been supported by German Research Foundation (DFG) and German Heart Foundation outside the submitted work. Petra Laeis, Paul-Egbert Reimitz, Rüdiger Smolnik and Wolfgang Zierhut are employees of Daiichi Sankyo Europe GmbH, Munich, Germany. Jan G. Tijssen reports personal fees from AstraZeneca, Bayer, and Boehringer Ingelheim outside the submitted work. Pascal Vranckx discloses personal fees from Daiichi Sankyo during the conduct of the study; and personal fees from AstraZeneca, Bayer Health Care, CLS Behring, and Terumo outside the submitted work.

Ethical approval The final study protocol and informed consent form were reviewed and approved by the ethics boards/institutional review boards and corresponding health authorities for all participating study sites.

Informed consent Written informed consent was obtained from patients for inclusion in this study.
Open Access This article is licensed under a Creative Commons Attribution 4.0 International License, which permits use, sharing, adaptation, distribution and reproduction in any medium or format, as long as you give appropriate credit to the original author(s) and the source, provide a link to the Creative Commons licence, and indicate if changes were made. The images or other third party material in this article are included in the article's Creative Commons licence, unless indicated otherwise in a credit line to the material. If material is not included in the article's Creative Commons licence and your intended use is not permitted by statutory regulation or exceeds the permitted use, you will need to obtain permission directly from the copyright holder. To view a copy of this licence, visit http://creativecommons.org/licenses/by/4.0/.

\section{References}

1. Capodanno D, Huber K, Mehran R, Lip GYH, Faxon DP, Granger CB, Vranckx P, Lopes RD, Montalescot G, Cannon CP, Ten Berg J, Gersh BJ, Bhatt DL, Angiolillo DJ (2019) Management of Antithrombotic Therapy in Atrial Fibrillation Patients Undergoing PCI: JACC State-of-the-Art Review. J Am Coll Cardiol 74(1):83-99. https://doi.org/10.1016/j.jacc.2019.05.016

2. Vranckx P, Valgimigli M, Eckardt L, Tijssen J, Lewalter T, Gargiulo G, Batushkin V, Campo G, Lysak Z, Vakaliuk I, Milewski K, Laeis P, Reimitz PE, Smolnik R, Zierhut W, Goette A (2019) Edoxaban-based versus vitamin $\mathrm{K}$ antagonist-based antithrombotic regimen after successful coronary stenting in patients with atrial fibrillation (ENTRUST-AF PCI): a randomised, openlabel, phase 3b trial. Lancet 394(10206):1335-1343. https://doi. org/10.1016/S0140-6736(19)31872-0

3. Cannon CP, Bhatt DL, Oldgren J, Lip GYH, Ellis SG, Kimura T, Maeng M, Merkely B, Zeymer U, Gropper S, Nordaby M, Kleine E, Harper R, Manassie J, Januzzi JL, Ten Berg JM, Steg PG, Hohnloser SH, Committee R-DPS, Investigators (2017) Dual antithrombotic therapy with dabigatran after PCI in atrial fibrillation. N Engl J Med 377(16):1513-1524. https://doi.org/10.1056/ NEJMoa1708454

4. Gibson CM, Mehran R, Bode C, Halperin J, Verheugt FW, Wildgoose P, Birmingham M, Ianus J, Burton P, van Eickels M, Korjian S, Daaboul Y, Lip GY, Cohen M, Husted S, Peterson ED, Fox KA (2016) Prevention of bleeding in patients with atrial fibrillation undergoing PCI. N Engl J Med 375(25):2423-2434. https:// doi.org/10.1056/NEJMoa1611594

5. Lopes RD, Heizer G, Aronson R, Vora AN, Massaro T, Mehran R, Goodman SG, Windecker S, Darius H, Li J, Averkov O, Bahit MC, Berwanger O, Budaj A, Hijazi Z, Parkhomenko A, Sinnaeve P, Storey RF, Thiele H, Vinereanu D, Granger CB, Alexander JH, Investigators A (2019) Antithrombotic therapy after acute coronary syndrome or PCI in atrial fibrillation. N Engl J Med 380(16):1509-1524. https://doi.org/10.1056/NEJMoa1817083

6. Valgimigli M, Bueno H, Byrne RA, Collet JP, Costa F, Jeppsson A, Juni P, Kastrati A, Kolh P, Mauri L, Montalescot G, Neumann FJ, Petricevic M, Roffi M, Steg PG, Windecker S, Zamorano JL, Levine GN, Group ESCSD, Guidelines ESCCfP, Societies ESCNC (2018) 2017 ESC focused update on dual antiplatelet therapy in coronary artery disease developed in collaboration with EACTS: The Task Force for dual antiplatelet therapy in coronary artery disease of the European Society of Cardiology (ESC) and of the European Association for Cardio-Thoracic Surgery (EACTS). Eur Heart J 39(3):213-260. https://doi.org/10.1093/ eurheartj/ehx419

7. Priori SG, Blomstrom-Lundqvist C, Mazzanti A, Blom N, Borggrefe M, Camm J, Elliott PM, Fitzsimons D, Hatala R, Hindricks 
G, Kirchhof P, Kjeldsen K, Kuck KH, Hernandez-Madrid A, Nikolaou N, Norekval TM, Spaulding C, Van Veldhuisen DJ (2016) 2015 ESC guidelines for the management of patients with ventricular arrhythmias and the prevention of sudden cardiac death. Rev Esp Cardiol (Engl Ed) 69(2):176. https://doi. org/10.1016/j.rec.2016.01.001

8. Goette A, Merino JL, De Caterina R, Huber K, Heidbuchel H, Jin J, Lip GYH (2020) Effect of concomitant antiplatelet agents on clinical outcomes in the edoxaban vs warfarin in subjects undergoing cardioversion of atrial fibrillation (ENSURE-AF) randomized trial. Clin Res Cardiol. https://doi.org/10.1007/s00392-020-01635 $-8$

9. Lip GY, Nieuwlaat R, Pisters R, Lane DA, Crijns HJ (2010) Refining clinical risk stratification for predicting stroke and thromboembolism in atrial fibrillation using a novel risk factorbased approach: the euro heart survey on atrial fibrillation. Chest 137(2):263-272. https://doi.org/10.1378/chest.09-1584

10. Merino JL, Lip GYH, Heidbuchel H, Cohen AA, De Caterina R, de Groot JR, Ezekowitz MD, Le Heuzey JY, Themistoclakis S, Jin J, Melino M, Winters SM, Merkely B, Goette A (2019) Determinants of left atrium thrombi in scheduled cardioversion: an ENSURE-AF study analysis. Europace 21(11):1633-1638. https://doi.org/10.1093/europace/euz213

11. Peng H, Sun Z, Chen H, Zhang Y, Ding X, Zhao XQ, Li H (2019) Usefulness of the CHA2DS2-VASc score to predict adverse outcomes in acute coronary syndrome patients without atrial fibrillation undergoing percutaneous coronary intervention. Am J Cardiol 124(4):476-484. https://doi.org/10.1016/j.amjcard.2019.05.036

12. Goette A, Lip GYH, Jin J, Heidbuchel H, Cohen AA, Ezekowitz M, Merino JL (2020) Differences in thromboembolic complications between paroxysmal and persistent atrial fibrillation patients following electrical cardioversion (From the ENSURE-AF Study). Am J Cardiol. https://doi.org/10.1016/j.amjcard.2020.06.046

13. Vranckx P, Lewalter T, Valgimigli M, Tijssen JG, Reimitz PE, Eckardt L, Lanz HJ, Zierhut W, Smolnik R, Goette A (2018) Evaluation of the safety and efficacy of an edoxaban-based antithrombotic regimen in patients with atrial fibrillation following successful percutaneous coronary intervention (PCI) with stent placement: Rationale and design of the ENTRUST-AF PCI trial. Am Heart J 196:105-112. https://doi.org/10.1016/j. ahj.2017.10.009

14. Lee KT, Chang SH, Yeh YH, Tu HT, Chan YH, Kuo CT, See LC (2018) The CHA(2)DS(2)-VASc score predicts major bleeding in non-valvular atrial fibrillation patients who take oral anticoagulants. J Clin Med. https://doi.org/10.3390/jcm7100338

15. Alvarez-Alvarez B, Raposeiras-Roubin S, Abu-Assi E, CambeiroGonzalez C, Gestal-Romani S, Lopez-Lopez A, Bouzas-Cruz N, Castineira-Busto M, Saidhodjayeva O, Redondo-Dieguez A, Pereira Lopez E, Garcia-Acuna JM, Gonzalez-Juanatey JR (2014)
Is 6-month GRACE risk score a useful tool to predict stroke after an acute coronary syndrome? Open Heart 1(1):e000123. https:// doi.org/10.1136/openhrt-2014-000123

16. Lopes RD, Leonardi S, Wojdyla DM, Vora AN, Thomas L, Storey RF, Vinereanu D, Granger CB, Goodman SG, Aronson R, Windecker S, Thiele H, Valgimigli M, Mehran R, Alexander JH (2020) Stent thrombosis in patients with atrial fibrillation undergoing coronary stenting in the AUGUSTUS Trial. Circulation 141(9):781783. https://doi.org/10.1161/CIRCULATIONAHA.119.044584

17. Vranckx P, Valgimigli M, Eckardt L, Lewalter T, Unikas R, Marin F, Schiele F, Laeis P, Reimitz PE, Smolnik R, Zierhut W, Tijssen J, Goette A (2020) Edoxaban in atrial fibrillation patients with percutaneous coronary intervention by acute or chronic coronary syndrome presentation: a pre-specified analysis of the ENTRUSTAF PCI trial. Eur Heart J. https://doi.org/10.1093/eurheartj/ehaa6 17

18. Atar D, Berge E, Le Heuzey JY, Virdone S, Camm AJ, Steffel J, Gibbs H, Goldhaber SZ, Goto S, Kayani G, Misselwitz F, Stepinska J, Turpie AGG, Bassand JP, Kakkar AK (2020) The association between patterns of atrial fibrillation, anticoagulation, and cardiovascular events. Europace 22(2):195-204. https://doi. org/10.1093/europace/euz292

19. Goette A, Kalman JM, Aguinaga L, Akar J, Cabrera JA, Chen SA, Chugh SS, Corradi D, D’Avila A, Dobrev D, Fenelon G, Gonzalez M, Hatem SN, Helm R, Hindricks G, Ho SY, Hoit B, Jalife J, Kim YH, Lip GY, Ma CS, Marcus GM, Murray K, Nogami A, Sanders P, Uribe W, Van Wagoner DR, Nattel S, Document R (2016) EHRA/HRS/APHRS/SOLAECE expert consensus on atrial cardiomyopathies: definition, characterization, and clinical implication. Europace 18(10):1455-1490. https://doi.org/10.1093/ europace/euw 161

20. Bukowska A, Spiller L, Wolke C, Lendeckel U, Weinert S, Hoffmann J, Bornfleth P, Kutschka I, Gardemann A, Isermann B, Goette A (2017) Protective regulation of the ACE2/ACE gene expression by estrogen in human atrial tissue from elderly men. Exp Biol Med (Maywood) 242(14):1412-1423. https://doi. org/10.1177/1535370217718808

21. Goette A, Bukowska A, Dobrev D, Pfeiffenberger J, Morawietz $\mathrm{H}$, Strugala D, Wiswedel I, Rohl FW, Wolke C, Bergmann S, Bramlage P, Ravens U, Lendeckel U (2009) Acute atrial tachyarrhythmia induces angiotensin II type 1 receptor-mediated oxidative stress and microvascular flow abnormalities in the ventricles. Eur Heart J 30(11):1411-1420. https://doi.org/10.1093/eurheartj/ ehp046

22. Reilly SN, Jayaram R, Nahar K, Antoniades C, Verheule S, Channon KM, Alp NJ, Schotten U, Casadei B (2011) Atrial sources of reactive oxygen species vary with the duration and substrate of atrial fibrillation: implications for the antiarrhythmic effect of statins. Circulation 124(10):1107-1117. https://doi.org/10.1161/ CIRCULATIONAHA.111.029223

\section{Affiliations}

\section{Andreas Goette ${ }^{1,2,3} \cdot$ Lars Eckardt $^{3,4} \cdot$ Marco Valgimigli $^{5}$. Thorsten Lewalter ${ }^{3,6,7} \cdot$ Petra Laeis $^{8} \cdot$ Paul-Egbert Reimitz $^{8}$. Rüdiger Smolnik ${ }^{8}$. Wolfgang Zierhut ${ }^{8}$. Jan G. Tijssen ${ }^{9,10} \cdot$ Pascal Vranckx $^{11}$}

\author{
Lars Eckardt \\ lars.eckardt@ukmuenster.de \\ Marco Valgimigli \\ vlgmrc@unife.it \\ Thorsten Lewalter \\ th.lewalter@uni-bonn.de
}

\author{
Petra Laeis \\ Petra.Laeis@daiichi-sankyo.eu \\ Paul-Egbert Reimitz \\ Paul-Egbert.Reimitz@daiichi-sankyo.eu \\ Rüdiger Smolnik \\ Ruediger.Smolnik@daiichi-sankyo.eu
}


Wolfgang Zierhut

Wolfgang.Zierhut@daiichi-sankyo.eu

Jan G. Tijssen

tijssenj@outlook.com

Pascal Vranckx

pascal.vranckx@iccuhasselt.be

1 Medizinische Klinik II: Kardiologie Und Intensivmedizin, St. Vincenz-Krankenhaus, Am Busdorf 2, 33098 Paderborn, Germany

2 Working Group of Molecular Electrophysiology, University Hospital Magdeburg, Magdeburg, Germany

3 Atrial Fibrillation Network, Munster, Germany

4 Division of Electrophysiology, Department of Cardiology and Angiology, University of Munster, Munster, Germany
5 Department of Cardiology, Inselspital, Bern University Hospital, University of Bern, Bern, Switzerland

6 Department of Cardiology, Hospital Munich South, Munich, Germany

7 University of Bonn, Bonn, Germany

8 Daiichi Sankyo Europe, Munich, Germany

9 Department of Cardiology, Amsterdam University Medical Centers, University of Amsterdam, Amsterdam, The Netherlands

10 Cardialysis, Rotterdam, The Netherlands

11 Department of Cardiology and Intensive Care, Jessa Ziekenhuis, Faculty of Medicine and Life Sciences at the Hasselt University, Hasselt, Belgium 